\title{
La violencia política contra los comunistas tras la guerra civil en Costa Rica (1948-1949)
}

\section{Silvia Elena Molina Vargas ${ }^{1}$}

\section{Resumen}

Recepción: 13 de junio de 2017 / Aceptación: 27 de noviembre de 2017

El presente artículo tiene como propósito explicar la represión política que sufrieron los comunistas costarricenses durante la posguerra, específicamente en los meses de gobierno de la Junta presidida por José Figueres Ferrer. Para desarrollar esta investigación se utilizaron los periódicos La Nación, Diario de Costa Rica y La Prensa Libre, expedientes del Archivo Nacional de Costa Rica y del Archivo Judicial, así como memorias de personas que vivieron en la época. La investigación prueba que los comunistas experimentaron diferentes niveles de intensidad en la represión, con momentos álgidos que incluyeron asesinatos, de acuerdo con las dinámicas de la Junta de Gobierno y la influencia de los grupos anticomunistas.

\section{Palabras clave}

Comunismo; violencia política; guerra civil; anticomunismo; Figueres Ferrer

\section{Abstract}

This article explains the political repression suffered by the Costa Rican communists during the postwar period, specifically in the months of governance of the "Junta" chaired by José Figueres Ferrer. To develop this research, La Nación, Diario de Costa Rica and La Prensa Libre newspapers, records of the National Archive of Costa Rica and the Judicial Archive, and memories of people who lived at the time were used. Research shows that Communists experienced different levels of intensity in the repression, with high points that included murders, depending on the dynamics of the "Junta" and the influence of the anti-communist groups.

\section{Keywords}

Communism; political violence; civil war; anti-communism; Figueres Ferrer

\section{Resumo}

Este artigo tem como objetivo explicar a repressão política sofrida pelos comunistas da Costa Rica durante a posguerra, especificamente nos meses de governação do "Junta" presidida por José Figueres Ferrer. Para desenvolver esta pesquisa jornais

1 Costarricense. Máster en Historia por la Universidad de Costa Rica (UCR). Docente de la Escuela de Historia, UCR. Correo electrónico: silvia_molinav@yahoo.com 
usado La Nación, Diario de Costa Rica e La Prensa Libre, foram utilizados registros dos Arquivos Nacionais da Costa Rica e do Arquivo Judicial, e memórias de pessoas que viveram na época. A pesquisa mostra que os comunistas experimentaram diferentes níveis de intensidade durante a repressão, com pontos altos que incluíram assassinatos, de acordo com a dinâmica do "Junta de Gobierno" e da influência dos grupos anti- comunistas.

\section{Palavras chave}

Comunismo; violência política; guerra civil; anticomunismo; Figueres Ferrer

\section{Introducción}

Después de la guerra civil de 1948, se construyó en Costa Rica una historia oficial de la década de 1940, desde la perspectiva de los vencedores, cimentada en una intelectualidad socialdemócrata que tuvo un importante arraigo institucional en la segunda mitad del siglo XX y, en particular, en la versión que José Figueres Ferrer (1906-1990) construyó sobre la guerra, al presentarse a sí mismo como el caudillo que por primera vez había derrotado al comunismo en América Latina (Díaz, 2015, p. 253). De esta forma, Figueres pasó a convertirse en un "héroe", "ciudadano del siglo" y un líder gracias a quien la niñez costarricense nunca tendría que volver a combatir en una guerra (Obregón, La Nación, 10 de enero de 2015, 28A). Los líderes opositores, Rafael Ángel Calderón Guardia (1900-1970) y Manuel Mora Valverde (19091994), fueron convertidos también en caudillos y beneméritos de la patria, y las reformas sociales asociadas a ellos fueron exaltadas, a la par de las disposiciones de la Junta de Gobierno que presidió Figueres, como un solo conjunto de medidas reformistas.

Para Eugenio Rodríguez, "la Junta de Gobierno, en su gestión de año y medio, marca ciertas orientaciones básicas para el futuro: modernización administrativa, absoluto respeto de los resultados electorales, desarrollo económico, fortalecimiento y ampliación de las leyes sociales" (2003, p. 251). De esta forma, dicha historia oficial se encargó de exaltar el proyecto socialdemócrata impulsado por el sector figuerista después de la guerra, y de vincularlo decididamente a la década de 1940, invisibilizando aquellos elementos históricos que descuadrarán en este relato.

Iván Molina, refiriéndose a un texto de Guillermo Villegas Hoffmeister (1998), ha señalado las principales falencias de esta versión oficial sobre la década de 1940: la presunción de una corrupción generalizada (y no probada) durante el gobierno de Calderón Guardia; el uso selectivo de datos, que enfatiza los supuestos fraudes en las elecciones de 1942 y 1944, pero que no problematiza el fraude y sus contradicciones en los comicios de 1948; la ausencia de un análisis sobre las quejas de calderonistas y comunistas respecto a su imposibilidad de votar en 1948; además, el argumento de que la guerra era 
inevitable, desmentido por otras investigaciones históricas ${ }^{2}$, y la disminución o disimulo del número de muertos del conflicto (2000, pp. 192-195).

\section{La violencia inmediata tras la guerra civil}

La guerra civil de 1948 concluyó con un acuerdo entre el gobierno de Teodoro Picado y las fuerzas figueristas, mediado por los embajadores de México y Estados Unidos. No obstante, los comunistas costarricenses cumplieron un papel central en este pacto, pues al formar parte de los sectores perdedores de la guerra, quisieron asegurar que su organización política sería respetada y que sus miembros no serían perseguidos.

Sin embargo, a pesar de que la historia oficial lo ha disimulado, el pacto que puso fin al conflicto no fue suficiente para evitar la represión, y la promesa figuerista de impedir la persecución no se respetó. Los aires de revancha de la posguerra eran difíciles de controlar. Según la prensa, debía sustituirse inmediatamente "al gobierno comunizado de Calderón, Picado y Mora", en aras de visibilizar "un gran sector del pueblo, el verdadero pueblo costarricense" (Llegaron ayer dos representantes..., Diario de Costa Rica, $1^{\circ}$ de junio de 1948, p. 1). Aunado a ello, en el contexto de inicio de la Guerra Fría, se evidenció una necesidad externa de plegarse a los lineamientos anticomunistas propuestos desde Washington, los cuales permitieron convertir a los "camaradas" en los "amenazantes internos", posición que justificó sancionar al comunismo durante las décadas subsiguientes (González, 2005, p. 6).

La Junta, durante su gobierno de 18 meses, toleró la violencia contra los perdedores. Los simpatizantes de la izquierda fueron víctimas de una constante persecución, la cual se tradujo en insultos, agresiones, encarcelamientos y amenazas contra su vida (Herrera, Mora \& Gamboa, 1971, p. 37), que se realizaron utilizando como justificación su "peligrosa" filiación política.

Tras la culminación del conflicto y una vez entregadas las armas, los comunistas fueron objeto de un ataque armado ocasionado por los figueristas en las cercanías del Parque Central, agresión en la que falleció una persona (Díaz, 2015, p. 298). El 29 de abril de 1948, un día después del Desfile de la Victoria figuerista en San José, varios líderes vanguardistas emprendieron su salida del país en dirección hacia México, entre ellos Manuel Mora, Carmen Lyra y Judith Ferreto; sin embargo, el avión en el que viajaban fue objeto de disparos de ametralladora al salir del Aeropuerto en La Sabana (El Gobierno actual desaprueba..., La Prensa Libre, 30 de abril de 1949, pp. 1 y 8; Salas, 1998, p. 186). El supuesto objetivo de los atacantes era capturar a Mora y fusilarlo, una acción que Ortuño (s. f.) les atribuyó a Max “Tuta” Cortés, Guillermo Martí y Rodrigo Paniagua, entre otros, catalogados como "termocéfalos", en una posible

2 Al respecto, consultar las investigaciones de Díaz (2015) y Solís $(2008,2013)$. 
referencia a los elementos más belicosos del Ejército de Liberación Nacional. El atentado resultó infructuoso y el avión continuó su viaje.

A causa de los daños, la aeronave debió recalar en Panamá; allí le decomisaron a Mora documentación múltiple, entre la que figuró una carta de Benjamín Núñez donde se aludía a los términos en que se negoció el fin de la guerra (Manuel Mora hecho preso..., La Prensa Libre, 30 de abril de 1948, pp. 1 y 6). Tras la escala obligatoria en Panamá, los líderes comunistas se enrumbaron hacia La Habana, Cuba, donde nuevamente fueron apresados al llegar al aeropuerto. En esa oportunidad, y según informó la prensa, un teniente del ejército y un soldado fueron quienes "tomaron bajo su protección" a los comunistas (Manuel Mora afirmó ayer..., Diario de Costa Rica, $1^{\circ}$ de mayo de 1948, pp. 1 y 2). Después de este suceso, viajaron hacia México.

De forma ulterior, el militante Arnoldo Ferreto se referiría a la situación que vivían los vanguardistas y a las amenazas que recibieron:

la Junta de Gobierno nos hizo saber que estábamos amenazados de muerte, que debíamos por nuestra propia seguridad, acceder "voluntariamente" a abandonar el país. Para ablandarnos, se nos ofrecía darnos visa para el regreso dos meses después, cuando ya la marea de pasiones hubiera bajado (Vargas, s. f., p. 17).

El contexto inmediato posterior a la guerra fue de incertidumbre y dolor para los militantes, ante la persecución desplegada contra ellos. Arnoldo Ferreto y Carlos Luis Fallas fueron apresados de manera casi inmediata (Ferreto, 1984, p. 104; Pérez, 1998, p. 292). Fernando Chaves Molina relató que cuando fue sacado de su casa al finalizar la guerra, le quebraron las costillas y le hirieron el rostro mientras era trasladado a la "Peni"; luego fue operado [en el hospital] a causa de las heridas (Chaves, 2002, p. 264). Rodolfo Cerdas Cruz rememoró la violencia que utilizaron cuando arrestaron a sus padres, tras registrar su casa y quemar libros y pinturas. Menciona haber pasado penurias y hambre en aquellos días (Cerdas, 2001, pp. 157-161). Álvaro Montero Vega narró la detención agresiva de la que fue víctima mientras se encontraba refugiado en la casa de sus padres, lo cual le significó su arresto por tres meses (Aguilar, 2013, pp. 80-82). Por su parte, Eduardo Mora relató que a fines de abril, el candidato a diputado vanguardista Adán Guevara (quien había participado en los combates de 1948) fue detenido en Liberia y se le había intentado asesinar mediante ahorcamiento, pero se habría salvado por la acción de una tercera persona ajena al conflicto (Mora, 2000, p. 158).

A pesar de la violencia que se utilizó en el trato hacia los vanguardistas, la prisión también sirvió para fortalecer los lazos del grupo y para desplegar espacios de solidaridad ante circunstancias adversas. Elsa Sáenz Ferreto narró que, siendo niña, acompañaba a su madre a la Penitenciaría, a donde le llevaban almuerzo y ropa a su padre Carlos Luis Sáenz, quien se encontraba detenido. Al respecto agrega: "aún recuerdo el salón circular donde nos juntábamos los familiares de todos los dirigentes encarcelados, los Braña, los Carballo, 
los Fallas, los Cordero ... y otros muchos. Saludos, abrazos, valentía y orgullo" (Sáenz, 1998, p. 27). Por su parte, la dirigente Luisa González explicó que después de la guerra debieron ayudar económicamente a las familias de los presos, así como a los excombatientes que tenían necesidades por haber dedicado sus esfuerzos en la guerra o haber perdido sus empleos. Mientras otros comunistas debieron permanecer escondidos en San José, pues el regreso a sus pueblos de origen podía significar un riesgo para sus vidas, dada la represión que se estaba experimentando (Contreras, 2010, p. 87).

La actitud anticomunista no se dirigió de manera exclusiva contra las reconocidas figuras del grupo. Este proceder se aplicó para cualquier persona que se sospechara poseía algún tipo de vínculo con los marxistas, como ocurrió el 24 de abril de 1948, cuando se detuvo a Antonio Valerín. Descrito por los medios como una persona de filiación comunista y a quien, de manera presunta, ese día le decomisaron "un gran arsenal" compuesto por máuseres, parque, revólveres, bombas y mercadería, hecho que justificó su arresto (Somoza vino a Costa Rica..., Diario de Costa Rica, 25 de abril de 1948, p. 4).

A inicios de mayo, fueron detenidos varios dirigentes comunistas, entre ellos Arnoldo Ferreto, Adolfo Braña, Fernando Chaves, Manuel Moscoa y Antonio Valerín, quien de forma previa ya había sido capturado. Según informó La Prensa Libre, el arresto se dio porque ellos

mantuvieron una actitud de beligerancia en el anterior gobierno y mientras contaron con el respaldo de la fuerza pública, en muchos casos hasta abusando de ese respaldo y cometiendo actos que ahora les van a ser planteados para que respondan sobre su culpabilidad (Detenidos en la Penitenciaría..., La Prensa Libre, 4 de mayo de 1948, p. 1).

Trinidad Vargas Rojas, esposa de Chaves, envió un escrito a la Corte Suprema de Justicia aduciendo que era falso que se le estuviera "prestando la protección" que de forma presunta él mismo llegó a solicitar. Vargas señaló que el 6 de mayo:

Por dos ocasiones llegaron a mi casa autoridades de policía a llevarse a mi marido, lo que no hicieron por no encontrarse en aquellos momentos él en su casa. Cuando más tarde él llegó, le comuniqué la situación, advirtiéndole que dichas autoridades me habían dicho que más tarde volverían por él. Como a mi marido en su primera detención practicada días antes, sin motivo alguno se le atacó brutalmente por la autoridad, causándole lesiones, de esta vez prefirió adelantarse (Archivo Judicial, Expediente No. 379, 1948, f. 6).

A raíz del ambiente tenso posterior a la guerra, los comunistas buscaron rearticular sus esfuerzos de organización, establecer estrategias para mantener su presencia pública y defenderse de los ataques, aún cuando muchos de ellos carecían de los medios económicos. Por ello, empezaron a circular su semanario Trabajo de manera clandestina. De esta forma, los vanguardistas instaban a sus partidarios a tener una actitud mesurada y defensiva ante 
la situación que atravesaban, a no responder la violencia directa que ejercían los ganadores de la guerra e, inclusive, hicieron un llamado a permitir que la Junta desarrollara sus proyectos, al aducir que: "no queremos estorbar en forma alguna a los buenos propósitos del gobierno" (No responder a la provocación..., Trabajo No. 1, mayo de 1948, p. 1).

Llama la atención que los comunistas, escasamente a un mes de concluida la guerra, consideraran aceptables los propósitos del grupo en el poder, el que había ejecutado su desplazamiento, persecución y encarcelamiento. Los vanguardistas se hallaban en una posición vulnerable y creían necesario aminorar los roces con la nueva administración, a la vez que solicitaban a sus partidarios abstenerse de acciones violentas que dificultaran aún más la difícil etapa que atravesaban.

No obstante, los militantes también denunciaron que la represión fue enérgica en los primeros meses de la posguerra, pues se declaró ilegal su medio de comunicación escrita, se cerraron imprentas e, inclusive, no fue posible emitir más la emisora de radio "Ecos del 56" (Contreras \& Cerdas, 1988, p. 173). Además, mediante los materiales clandestinos que lograron reproducir, los comunistas alcanzaron a denunciar la persecución de la que eran objeto y trataron de proteger a los suyos ante las arbitrariedades del nuevo gobierno. Este grupo evidenció la persecución e incluso el asesinato que se cometía contra los ciudadanos, al margen de la legalidad y al amparo de la suspensión de las garantías individuales decretada por la Junta de Gobierno, además de la muerte de personas que se encontraban detenidas bajo la tutela de las nuevas autoridades. Los vanguardistas apelaban al Ministro de Seguridad, Edgar Cardona, exigiendo el fin de la represión así como sanciones para los responsables, pero a la vez sugerían coordenadas comunes de interpretación del pasado y de la idiosincrasia costarricense: "el prestigio de nuestro pueblo, que se deriva de su apego a todos los principios de la Civilización, debe salir limpio de esta lucha fratricida" (Los actos que ayer..., Trabajo No. 1, mayo de 1948, p. 1).

El 19 de mayo la Junta creó el Tribunal de Sanciones Inmediatas (Quirós, 1989, p. 3), lo que facilitó la persecución y detención de comunistas. De acuerdo con Acuña, Alberto Martén atribuía la creación de estos tribunales al anticomunismo de uno de los miembros de la Junta, quien "insistía continuamente en la cacería de brujas comunistas. Siempre aparecía con listas de empleados indeseables y de canallas mariachis" (1990, p. 352).

A los dirigentes comunistas Adolfo Braña, así como a Luis Carballo y a su esposa Pilar Bolaños, se les acusó de provocar un incendio que tuvo lugar el 18 de mayo. La prensa informó que los tres vanguardistas se presentaron ante los juzgados para aclarar que su grupo no tuvo nada que ver con el incendio que pretendían atribuirles (No fueron presos..., La Prensa Libre, 19 de mayo de 1948, p. 4). Los medios de comunicación escrita buscaron for- 
talecer la idea de que las víctimas eran quienes habían sufrido la represión del gobierno anterior, mientras que los victimarios eran los miembros de esa administración, en particular los comunistas. Las acciones de los vanguardistas recibieron entonces una atención importante por parte de la Junta. Por ejemplo, el 27 de mayo, en la sesión No. 7, se discutió un informe sobre el accionar de este grupo en el país con el fin de tomar medidas represivas, por lo cual se decidió romper relaciones con la URSS (Acuña, 1997, p. 17).

\section{Los asesinatos de Edwin Vaglio y Horacio Montiel}

Además de los constantes arrestos, persistía la inseguridad de los comunistas por su integridad física, pues "se produjeron asesinatos de compañeros que fueron sacados de la Penitenciaría durante la noche" (Ferreto, 1987, p. 37). Los comunistas se veían en una situación de incertidumbre, donde los detenidos eran objeto de liberación, pero capturados de manera inmediata, un evento al que pasaron a designar como los "viajes de ida y vuelta" (Mora, s. f., p. 8).

De esta situación fueron víctimas los comunistas Edwin Vaglio y Horacio Montiel, quienes se presume, fueron asesinados a mediados de mayo de 1948, en el denominado crimen de "La Cangreja". Otras fuentes se refieren a tres personas fallecidas. Villegas menciona que Vaglio, Montiel y Mónico Hernández habían incendiado el templo de Buenos Aires de Osa al finalizar la guerra, y por ello fueron luego fusilados (2008, p. 534). El padre de Edwin, Tobías Vaglio, sería también ultimado el 19 de diciembre de 1948 en el crimen del Codo del Diablo. Carlos Luis Fallas, quien había sido víctima de los constantes ingresos y salidas de la "Peni", comprobó, con alarma, cómo en una de esas oportunidades al regresar al penal:

Edwin Vaglio y Horacio Montiel también habían sido llamados el día anterior, y que no aparecían por ninguna parte. Entonces sí vi con toda claridad cuál era el verdadero objeto de esa repetida maniobra de los militares; porque Montiel y Vaglio no habían presentado Recurso ni hecho gestión alguna para recobrar su libertad. Muy pronto "La Hora" vino a comprobar mis sospechas, relatando el hallazgo en la carretera, en La Cangreja de Cartago, de dos cadáveres que, según la información, habían sido tan brutalmente golpeados y tiroteados que resultaba difícil su identificación (Fallas, 1952, p. 2).

Cuando Fallas se enteró de lo ocurrido a sus camaradas, elevó una acusación a la Corte Suprema de Justicia, el día 24 de mayo (Protestó la Corte..., Diario de Costa Rica, 25 de mayo de 1948, pp. 1 y 8). Un día después, la Corte remitió la denuncia al Juez correspondiente. El 26 de mayo, Fernando Cortés, Primer Comandante de la Penitenciaría, desmentía a Fallas a través de la prensa y aseguraba que no habían sido sacados presos del recinto en horas nocturnas, ni tampoco habían sido torturados o maltratados (Emplazo al comunista..., Diario de Costa Rica, 26 de mayo de 1948, pp. 1 y 5). Fallas argumentaría más tarde que él tuvo en sus manos un oficio, facilitado 
por Guillermo Cortés, el cual estaba firmado por el Capitán Carlos Lara y tenía el sello del Estado Mayor; en el documento, se solicitaba la salida de Montiel y Vaglio del penal (Fallas, 1952, p. 5).

Después de la denuncia de Fallas a la Corte, Diario de Costa Rica comenzó a informar sobre crímenes que se les achacaban a los comunistas, en particular a Montiel, con el fin de justificar los asesinatos. El 27 de mayo, Fausto Castillo denunciaba que había sido víctima de "las hordas gobiernistas que comandaba Montiel" (Mi hogar fue asaltado..., Diario de Costa Rica, 27 de mayo de 1948, p. 4), las cuales, durante la guerra, hurgaron en su casa ubicada en La Guácima y le robaron variadas pertenencias. El 29 de mayo, Jorge Rojas inculpaba a Montiel y a otros tres "mariachis" de un homicidio (Asesinato de Eduardo Fernández..., Diario de Costa Rica, 29 de mayo de 1948 , p. 7). Con estas acciones atribuidas a Montiel se pretendía justificar el crimen de La Cangreja.

Otras memorias de camaradas también se refirieron al hecho y corroboraron el ensañamiento contra los ultimados; pues en el caso de Vaglio, se dijo que fue asesinado a "culatazos" y que su cuerpo quedó "destruido", mientras la prensa publicaba en sus páginas que la muerte de Edwin se debió al atropello de un carro (Chaves, 2002, p. 272); entretanto, otras personas recordaron y cuestionaron cómo se trató de simular la muerte de Vaglio y Montiel con "otra cosa que no fuera crimen" (Valverde, 2001, p. 304). Fallas señaló que cuando él salió de prisión y visitó a la familia de Vaglio, una hermana le comentó las precarias condiciones en las que habían recibido el cuerpo, pero que no interpondrían la denuncia, pues ella y un hermano habían combatido a favor del figuerismo y desempeñaban entonces empleos públicos (Fallas, 1952, p. 2).

\section{El "peligro comunista" y los llamados a la moderación}

A partir de la violencia que habían recibido los vanguardistas, y los casos señalados, se suscitó la preocupación por posibles intentos de asesinato. Jaime Cerdas manifestó estas inquietudes en la denuncia que interpuso en defensa de Édgar Carvajal, donde alegó desconocimiento sobre su paradero:

según informes fidedignos que tengo, fue sacado anoche a altas horas de la noche y trasladado siempre detenido a otro lugar, porque no está en libertad

... Tanto los familiares de Carvajal Cabezas como yo, tememos por la suerte corrida por dicho ciudadano, ya que en ningún cuartel dan ahora cuenta de él, a pesar de no haber sido puesto en libertad (Archivo Judicial, Expediente No. 518,1948, f. 2).

La preocupación de los militantes no era gratuita, pues el $1^{\circ}$ de junio la prensa informó que los comunistas se encontraban en una "campaña de 
subversión" y que el día anterior habían sido detenidas 30 personas por esta causa (El comunismo en abierta campaña..., Diario de Costa Rica, 1 de junio de 1948, p. 8). Pilar Bolaños señaló que en el caso de la nueva detención de su cónyuge Luis Carballo, este "fue sacado de nuestra casa de habitación, en medio de un gran escándalo hecho por gentes armadas" (Archivo Judicial, Expediente No. 518, 1948, f. 3). Las memorias de la época muestran que las detenciones contra los vanguardistas se hacían con violencia y se afectaba a los familiares, incluso a los niños. Argüello (1954, pp. 63-64) narra que fue testigo de cómo las autoridades militares maltrataban a un niño que era el hijo de Carballo, cuando este y su esposa fueron encarcelados.

Estas acciones pretendían asociar el comunismo con una amenaza bélica constante para el país. Para muestra, el 3 de junio se informó que los izquierdistas planeaban alguna acción peligrosa en contra del gobierno y del orden público:

Entre los directores intelectuales del comunismo está Luis Carballo, quien desde ayer se le interroga por los miembros del servicio de inteligencia, debido a que en su poder se encontraron documentos que ponen en evidencia planes sobre futuras actividades subversivas del partido (Bajo interrogatorio..., Diario de Costa Rica, 3 de junio de 1948, p. 8).

El 18 de junio la Junta suspendió las garantías individuales, por lo que entre el 18 y el 19 de junio fueron arrestadas varias personas acusadas de ser comunistas, algunas de las cuales hacía pocos días habían sido liberadas (Archivo Judicial, Expedientes No. 379, 1948; No. 380, 1948; No. 417, 1948; No. 424, 1948). Las detenciones se articularon como prevención ante las informaciones que manejaba el gobierno: "es una medida defensiva, ya que la mayoría de estos elementos se venían reuniendo clandestinamente y celebrando conversaciones de carácter subversivo, como también, dedicándose a otras actividades peligrosas para la tranquilidad del país" (Detenidos anoche..., La Prensa Libre, 19 de junio de 1948, pp. 1 y 8). Mientras se justificó este accionar, La Prensa Libre informó sobre aproximadamente 60 personas detenidas, entretanto La Nación apuntó alrededor de 41 arrestos, dentro de los cuales sobresalieron Luis Carballo, Arnoldo Ferreto, Adolfo Braña, Álvaro Montero Vega y Manuel Moscoa (Fueron capturados ayer..., La Nación, 20 de junio de 1948, p. 6).

Con estas medidas el gobierno no solo reprimió, sino que se sumó a la creciente ola de criminalización puesta en marcha contra los camaradas, que se justificó por parte de diversos sectores sociales y se evidenció en los medios de comunicación escrita. Es por ello que en un discurso que José Figueres pronunció el 29 de junio, este argumentó:

No puede acusarse al gobierno actual de fomentar la impunidad ante los graves delitos cívicos recién pasados, porque ya hemos tomado medidas punitivas de rigor extraordinario. Hay varios centenares de pecadores que se exiliaron ellos mismos, y que hoy sufren la melancolía del ostracismo. Hay doscientas 
personas y firmas comerciales cuyos bienes están intervenidos mientras se realizan las investigaciones pertinentes, y que están entre tanto sufriendo el castigo que significa la humillación de ver sus nombres en las listas. Hay en la sepultura un millar de soldados y oficiales que cometieron el delito de esgrimir las armas en defensa del deshonor de veintisiete diputados, y de la injusticia general de un régimen corrompido. ¿Por qué nos pide la opinión pública que llenemos las cárceles de reos políticos, si acabamos de luchar precisamente para que en Costa Rica no hubiera atropellos contra nadie? ¿Por qué nos exigen que impongamos el más inhumano de los castigos imaginables, que consiste en privar de trabajo a un delincuente, y del sustento cotidiano a una familia entera? El gobierno que yo presido no está dispuesto a asumir ante la historia la gravísima responsabilidad de una hostilidad interminable ante un sector de la población que constituyó hasta hace poco el grupo de los perdedores y que ya ha sido castigado, en nuestra opinión, con dureza suficiente (Figueres Ferrer, La Nación, $1^{\circ}$ de julio de 1948, pp. 12 y 13).

Figueres buscaba frenar la represión contra los perdedores sin parecer débil, mientras los militantes que eran encarcelados querían mostrar la persecución de la que eran víctimas y evidenciar el maltrato por parte de las nuevas autoridades: "A pesar de todo el esfuerzo oficial por ocultarlo, cada día se hace más evidente que vivimos en un régimen de terror oficialista" (¿Qué hubo en el asesinato..., Trabajo No. 6, julio de 1948, p. 3) y remachaban diciendo que "millares de oprimidos han rechinado los dientes en las cárceles de la 2a República" (jSalud, resistentes!, Trabajo No. 6, julio de 1948, p. 3). Los comunistas utilizaron el medio escrito clandestino Trabajo como una opción para dar a conocer las circunstancias de represión que experimentaban y la contradicción entre el discurso de la Junta de Gobierno y la realidad de las cárceles y los presos políticos (ver llustración 1). 


\section{llustración 1.}

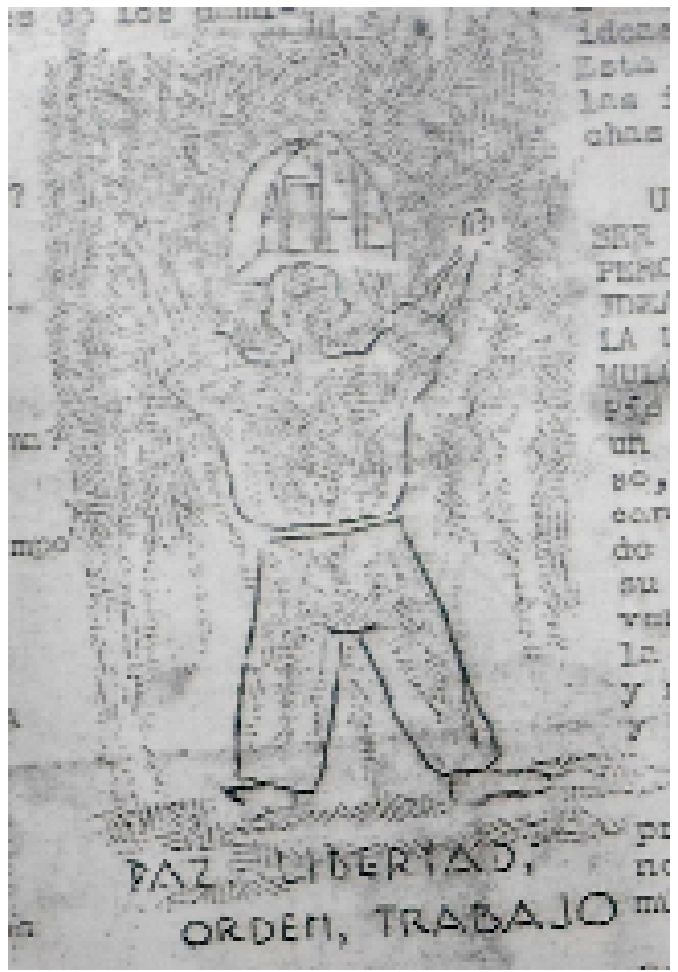

Fuente: Los dirigentes de Vanguardia Popular nuevamente encarcelados, Trabajo No. 3, junio 1948, p. 3.

La represión contra los vanguardistas, en este contexto, evidenció una importante contradicción. Mientras la Junta necesitaba legitimar sus proyectos económicos, como la nacionalización bancaria y el impuesto del 10\% a los capitales (por los cuales Figueres recibió acusaciones de ser comunista), hacía eco de las demandas anticomunistas de otros sectores de la sociedad y encarcelaba a los militantes. Por su parte, los comunistas denunciaban a la Junta por estos maltratos, pero, a la vez, a través de Trabajo y de los mecanismos que tenían a su alcance, defendían las medidas económicas que se estaban implementando, al considerar que tanto los impuestos como la banca nacionalizada eran beneficiosos para las clases populares.

A partir del decreto de ilegalización contra los comunistas del 17 de julio, se produjeron más detenciones. Esta maniobra la advirtieron de manera pronta 40 personas que fueron detenidas por llevar a cabo diferentes acciones, pero todas finalmente imputadas a causa de sedición en perjuicio del Estado, al pertenecer a una agrupación que había sido prohibida (Archivo Nacional de Costa Rica, Judicial Remesa 1660 No. 39, Exp. 388, 1948, ff. 3-5v; Archivo Judicial, Expediente No. 656, 1948). 
Otros militantes fueron detenidos como consecuencia de la portación de materiales "clandestinos" como el periódico Trabajo o al participar en reuniones que fueron catalogadas como subversivas. Durante el mes de agosto prosiguieron las capturas de personas vinculadas al comunismo, lo cual fue objeto de atención por parte de la prensa. Por ejemplo, los medios subrayaron cómo el 5 de agosto cinco maestras fueron detenidas en Puntarenas y luego interrogadas en el Tribunal de Sanciones Inmediatas, a causa de la publicación y distribución de una serie de hojas "clandestinas". La Prensa Libre enfatizó la amplitud de la red que los comunistas habían fraguado por todo el país para difundir su mensaje, con la cual, y de acuerdo con el periódico, "llevan intranquilidad a los hogares costarricenses" (Siguen las detenciones..., La Prensa Libre, 8 de agosto de 1948, pp. 1 y 10).

De nuevo, el 11 de agosto se informó sobre la captura de varias personas, entre ellas mujeres. Los medios informativos indicaron que las autoridades debieron trabajar mucho para confiscar la gran cantidad de propaganda desplegada y repartida por los comunistas, como hojas sueltas, folletos, libros y periódicos. Se mencionaron las detenciones de Emilia Prieto y María Esquivel en Puntarenas, y los maestros Tula Sandino y Miguel Ángel Palma en Cañas Gordas de Guanacaste, a los cuales se les decomisó material de divulgación y fueron llevados en avioneta a San José (La propaganda clandestina..., Diario de Costa Rica, 11 de agosto de 1948, pp. 1 y 6).

Con la publicación de estas noticias, la prensa fortaleció la imagen de "peligro para el país" que de manera supuesta representaban los comunistas, a la vez que enfatizó en el tamaño de la organización clandestina. Por ello, consideró encomiable el trabajo de las autoridades para dar con los hilos de una vasta red de actos subversivos que,

parecen guardar relación con los movimientos militares de que se acusa a los costarricenses que permanecen en el exilio voluntario. Fueron los primeros en sufrir interrogatorio, cabecillas de San José. Las mujeres destacan por su pasión y entusiasmo en defensa de la causa; a ellas ha sido menos fácil arrancarles declaraciones útiles y se muestran decididas a afrontar las consecuencias que su actitud sediciosa les acarree (La propaganda clandestina..., Diario de Costa Rica, 11 de agosto de 1948, pp. 1 y 6).

Pero, ¿cuál fue el común denominador de estos diferentes casos? En todos ellos los comunistas fueron increpados por sedición y eran ellos, como incriminados, quienes debían demostrar su inocencia. En tal sentido, los imputados y sus defensores fueron enfáticos en calificar la existencia de los Tribunales Especiales como un "verdugo", pues este no vino a "juzgar a los ciudadanos, sino a perseguirlos", siendo su existencia contraria a todas las tradiciones de la República. Del mismo modo, las personas legalmente cuestionadas descalificaron el hecho de ser juzgados "por hombres de un partido enemigo, generosamente pagados para aplicarnos a su arbitrio y sin ape144 lación, un grillete creado por los nuevos libertadores, que puede alcanzar 
el tamaño de 10 años de prisión" (Archivo Nacional de Costa Rica, Judicial Remesa 1660 No. 39, Exp. 388, 1948, ff. 28-28v).

Cuando los comunistas eran liberados volvían rápidamente a prisión (Aguilar, 2013, p. 83). Por ello, la cárcel se convirtió en un espacio donde interactuaban los calderonistas y los comunistas, unos meses antes compañeros de lucha, aliados por intereses comunes y, en esas circunstancias, sospechosos de atentar contra la seguridad del país. Las diferencias entre ellos eran evidentes, por lo que dirigentes calderonistas como el general Volio se referían a su detención como un estado de absoluta extrañeza, ya que en su criterio no había mayor locura que estar preso con los comunistas (Zúñiga, 1991, p. 366).

Dada la prohibición y las condiciones imperantes, se comprende por qué los vanguardistas buscaron exponer la actitud de la Junta durante el segundo semestre de 1948. Carlos Luis Fallas denunció constantemente los atropellos que recibía. En una nota pública dirigida de manera expresa a Figueres, el día 6 de octubre, Fallas detalló la violencia con la cual las autoridades ingresaron en la casa de sus familiares con el fin de localizarlo a él, amenazando con armas a sus parientes e, incluso, a los vecinos (Denuncia violentos procedimientos... Diario de Costa Rica, 6 de octubre de 1948, p. 5).

Arnoldo Ferreto se posicionó en la prensa sobre la situación que estaban viviendo. Defendió a sus compañeros Luis Carballo, Carlos Luis Fallas y otros más, quienes se encontraban detenidos por acusaciones de atentar contra el gobierno, argumentando que "no somos aventureros, sino luchadores responsables por la democracia y el bienestar popular" (Quiero hacer pública..., Diario de Costa Rica, 5 de octubre de 1948, p. 3).

\section{Diciembre de 1948: recrudecimiento de la represión y crimen del Codo del Diablo}

En los últimos meses del año 1948, el gobierno de la Junta debió enfrentar la amenaza de un ataque externo. En los medios se alimentaba la idea de una posible invasión antifiguerista desde Nicaragua. Por ello, las precauciones, en términos de seguridad, aumentaron y los comunistas experimentaron las consecuencias. En octubre de 1948, el gobierno ordenó una redada contra los "calderocomunistas" por un supuesto movimiento subversivo que se sospechaba estaba pronto a estallar. Temor que se agravó cuando en Esparza y en Guanacaste se decomisaron armas y se efectuaron allanamientos (Desde anoche se ordenó..., La Prensa Libre, 2 de octubre de 1948, pp. 1 y 3).

Sobre las constantes detenciones, resulta significativo el énfasis que la prensa le brindó a la clandestinidad del movimiento comunista, pues procuró ubicarlo siempre como una actividad "fuera de la ley". Ello ocurrió el 5 de octubre, cuando la Junta de Gobierno se reunió y brindó un informe sobre el intento 
de sublevación de un grupo de "caldero-comunistas"; al tiempo, que informó sobre la detención de personas quienes, al ser interrogadas, de manera presunta confesaron los planes subversivos. La prensa enfatizó la idea de que las autoridades actuaron para controlar cualquier infiltración armada que como fin se planteara alterar la paz interna o crear dificultades internacionales; a causa de lo anterior, el gobierno mantenía una vigilancia constante sobre puntos medulares en el país (Del malogrado complot..., Diario de Costa Rica, 6 de octubre de 1948, pp. 1 y 3).

Arnoldo Ferreto se apresuró a desmentir en la prensa que los comunistas tuvieran alguna relación con los preparativos militares contra Figueres (Ningún elemento responsable..., Diario de Costa Rica, 7 de octubre de 1948, p. 5). Los comunistas buscaron desligarse de los calderonistas y de cualquier intento de ataque armado contra la Junta, a la vez que pretendían el apoyo electoral para el Partido Constitucional. No obstante, dado el conflicto y las circunstancias políticas del mes de diciembre, los militantes no pudieron abstraerse de la represión.

A inicios de diciembre se suspendieron las garantías individuales y se aumentó la censura de los medios escritos y radiales que pudieran incitar a la rebelión (Salazar, 1981, p. 154), mientras que más personas vinculadas al comunismo fueron encarceladas. La Junta de Gobierno, con el fin de repeler el ataque calderonista desde Nicaragua, debió organizarse para la batalla.

Este fue un periodo que resultó difícil de enfrentar para el grupo de izquierda. Los comunistas advirtieron cómo las autoridades fortalecieron la violencia contra ellos y se cometieron varios abusos. Carlos Luis Fallas fue detenido y enviado a prisión el 9 de diciembre (Gran victoria..., Diario de Costa Rica, 9 de diciembre de 1948, pp. 1 y 4).

No obstante los actos más violentos se cometieron el 19 de diciembre. Ese día, Carlos Luis Fallas, Adolfo Braña, Luis Carballo, Jaime Cerdas y Arnoldo Ferreto fueron sacados luego de la medianoche de la Penitenciaría Central y, según las memorias de Cerdas (1993, pp. 173-176) y Ferreto (1987, p. 94), el objetivo de aquella acción era asesinarlos. Fue la intervención de Monseñor Sanabria, a instancias de la esposa de Cerdas, Olinda Cruz, la que habría salvado a los dirigentes vanguardistas de morir, pues el objetivo parecía ser descabezar el movimiento comunista costarricense aprovechando la excusa de la invasión (Solís, 2007-2008, p. 271).

No corrieron la misma suerte esa noche seis personas en la provincia de Limón. Los dirigentes sindicales vanguardistas Tobías Vaglio Sardí, Federico Picado Sáenz, Octavio Sáenz Soto y Lucio Ibarra Aburto, fueron asesinados en Siquirres, en la vuelta conocida como el Codo del Diablo. También murieron Narciso Sotomayor Ramírez y Álvaro Aguilar Umaña (apodado "Matatigres"). Los perpetradores del crimen fueron sus cuatro custodios, los cuales, de acuerdo con las declaraciones oficiales, los trasladaban a la 
Penitenciería en San José. Tres de los acusados por homicidio recibieron condenas de prisión de hasta 30 años, pero gracias a vínculos políticos y a la displicencia de las autoridades, lograron evadir sus penas y salir del país. No se conoció tampoco quiénes ordenaron asesinar a estas personas, y el crimen del Codo del Diablo quedó impune (Molina, 2017, p. 37; Archivo Judicial, Exps. No. 1 y No. 5, 1949; Benavides, 1968, p. 141).

Otros casos en la provincia de Limón reflejan la violencia de la coyuntura del mes de diciembre. Iván Horde, quien se encontraba preso en la cárcel de la localidad, desapareció sin conocerse su paradero (Archivo Judicial, Exp. No. 5, 1949) y José Matarrita fue asesinado por manifestar de manera pública su apoyo a Manuel Mora y a los comunistas (Contesta Arnoldo Ferreto..., Diario de Costa Rica, 27 de febrero de 1949, pp. 1 y 6).

Los insurrectos calderonistas también perpetraron asesinatos en esos días. Estos crímenes tuvieron en común que algunos de ellos se cometieron contra ciudadanos no involucrados de manera directa en las acciones militares. Así, por ejemplo, el 20 de diciembre -solo un día después de la masacre del Codo del Diablo- los alzados asesinaron a un grupo de civiles, la mayoría miembros de la Cruz Roja, en el lugar conocido como El Murciélago; suceso en el cual fallecieron seis personas: Antonio Facio Castro (médico), Jaime Gutiérrez Braun (ingeniero), Jorge Quesada González (sacerdote), Oscar Mainieri Ibarra (abogado), Edgar Ardón Brenes y Jorge Delgado Flores. E incluso, para el 25 de diciembre murieron cuatro personas más (Eloy Morúa Carrillo, Efraín Roldán Pérez, Bernal Vargas Facio y Víctor Manuel Víquez Arguedas) a manos de los levantados en armas (Tovar, 2008, pp. 34-35).

\section{El año 1949 y la dosificación de la violencia}

Después de la persecución de diciembre, los militantes volvieron a su trabajo de organización política. Según Cerdas (1993, p. 182), a partir de la puesta en marcha de la Asamblea Constituyente en enero, disminuyó la persecución hacia ellos y pudieron continuar organizándose, ya que la Junta de Gobierno perdió parte del poder que le daban los decretos y la actuación unilateral.

Por ello, durante los meses iniciales de 1949, las detenciones de los comunistas se encauzaron principalmente contra individuos que distribuían diferentes tipos de materiales impresos entre la población. El 24 de enero, por ejemplo, se detuvo a varias personas acusadas de participar en un "centro distribuidor de propaganda subversiva", siendo notoria la forma en que la prensa se plegaba a la posición oficial reproduciendo un discurso que arremetía constantemente contra los comunistas, quienes según La Prensa Libre "han redoblado sus esfuerzos tendientes siempre a llenar las mentes sencillas de odios contra la labor depuradora característica del nuevo 
régimen" (Las autoridades sobre pista..., La Prensa Libre, 25 de enero de 1949, pp. 1 y 3).

Hacia marzo de 1949 se evidenció un nuevo aumento en los casos de represión. El 25 de ese mes detuvieron a 15 personas por portar y distribuir propaganda escrita, específicamente Trabajo. No obstante, en la prensa se apuntó que las detenciones no se debieron únicamente a la distribución del material, ya que varios miembros de la agrupación venían siendo vigilados de cerca, máxime que estos hechos coincidían con las gestiones que se estaban realizando para el retorno de Manuel Mora y de otros líderes de la izquierda al país. Aquí entonces se utilizó de nuevo la estrategia del temor y el descrédito, subrayando "el sentimiento de intranquilidad" que suscitaba entre los habitantes este tipo de acciones por parte de los marxistas (Sorprendidos 15 comunistas..., Diario de Costa Rica, 25 de marzo de 1949, pp. 1 y 2).

Los decretos-ley se convirtieron en un instrumento vital de la Junta de Gobierno para desvirtuar a sus opositores ante la opinión pública, mientras le proporcionaban legitimidad a su estancia en el poder y le permitían mantener a los comunistas recluidos por un tiempo prudencial. Para los vanguardistas, Figueres intentó con estas acciones "conquistar la confianza y el apoyo de Washington" (Fallas, 2013, p. 190). Por su parte, la Junta se veía inmersa en un contexto convulso, al tener que responder a grupos de poder político al interior del país, y buscar congraciarse con el Departamento de Estado norteamericano.

Entre abril y junio de 1949 se dieron nuevos brotes de represión contra los comunistas. Según Schifter (1985, pp. 116-134), para el mes de abril los sectores conservadores se aliaron contra la Junta y denotaron su anticomunismo, pues los militantes de izquierda podían ser presentados como un peligro para la estabilidad democrática e institucional del país, situación que coincidió con el discurso anticomunista presente en la prensa.

La represión a partir de abril de 1949 irrumpió al calor de la infructuosa intentona de golpe de Estado comandada por el Ministro de Seguridad de la Junta, Edgar Cardona. La Nación le atribuía, en un principio, la responsabilidad del "Cardonazo" a los "caldero-comunistas" (El señor Presidente..., La Nación, 9 de abril de 1949, p. 5). El "Cardonazo" fue seguido de varios días de incertidumbre, espacio durante el cual incluso se mencionó la posibilidad de que la Junta entregara el poder de manera anticipada a Otilio Ulate (Entrega del poder..., Diario de Costa Rica, 21 de abril de 1949, pp. 1 y 6).

Al respecto, los comunistas consideraron que, bajo aquellas circunstancias, Figueres lo que pretendió fue que la Junta no cayera; por ello, salvó todos sus decretos-ley, afirmó las sentencias de los tribunales especiales y fabricó una nueva victoria militar (Fallas, Mora y Ferreto, s. f., p. 18). Pero, esas acciones fortalecieron la represión contra los perdedores, según lo evidenciaron las denuncias interpuestas por personas afines al comunismo. 
Rosa Venegas Campos, por ejemplo, presentó ante la Corte Suprema de Justicia un recurso de hábeas corpus en favor de Fernando Villalobos PadiIla, al tiempo que culpaba a las "fuerzas armadas" por actuar con violencia exagerada en el allanamiento de su habitación:

Fernando llegó a mi casa buscando refugio por cuanto la policía lo perseguía, yo le di ese asilo porque es amigo de mi marido. Minutos después llegaron varios números de Seguridad Pública revólver en mano y me amenazaron con matarme si no entregaba a Villalobos (Venegas, La Nación, $1^{\circ}$ de mayo de 1949, p. 9).

Las sospechas contra los comunistas podían extenderse a diferentes lugares del país, pues la portación de propaganda clandestina o la organización de reuniones, ya fuera sindicales u otras, cuyo propósito se desconocía, eran para el gobierno y la prensa prueba de esas acciones que reñían contra la legalidad (Cabe otorgar la excarcelación..., La Prensa Libre, 12 de mayo de 1949, p. 11; No hubo violencia..., Diario de Costa Rica, 26 de mayo de 1949, p. 5). Además, cualquier persona podía interponer e incluso recibir este tipo de denuncias; tal y como le ocurrió en junio al policía de Aguas Zarcas de San Carlos, quien debió defenderse de una acusación de comunismo (Archivo Nacional de Costa Rica, Gobernación No. 41745, 1949, f. 37). Para ese momento, el arresto de los militantes se entendía como un medio para garantizar la seguridad pública. Unas detenciones que, de acuerdo con el diputado Zeledón Brenes, "se aplican y cumplen sin violencia ni atropellos de ninguna naturaleza" (Reconoce la Asamblea..., Diario de Costa Rica, 26 de mayo de 1949, pp. 1 y 8), aunque en este caso, los arrestos a los que aludía Zeledón se realizaron para evitar una reunión de cinco personas de filiación comunista.

El discurso de la prensa costarricense se tornó más beligerante en contra del comunismo (Expulsión de líderes comunistas..., La Nación, 14 de mayo de 1949, p. 4; Excluido el comunismo..., Diario de Costa Rica, 25 de mayo de 1949, pp. 1-2; Disuelto el Partido Comunista..., Diario de Costa Rica, 24 de junio de 1949, p. 2), mientras a nivel internacional la condición adversa para este tipo de agrupaciones era evidente, pues por ejemplo, durante el primer semestre de 1949, se anularon una serie de partidos de izquierda en América Latina y se persiguió a sus integrantes. Algunos casos revelan este ambiente anticomunista: en El Salvador, se expulsó a los líderes de izquierda; en Colombia, se prohibieron los partidos políticos de esta tendencia, y en Chile, el presidente Gabriel González Videla declaró que acabaría con el comunismo, mientras en México se reprimió a los militantes y se ilegalizó su partido (Meyer, 2010; Servin, 2014; El Presidente de Chile..., Diario de Costa Rica, 25 de junio de 1949, p. 6). 


\section{Conclusión}

Como resultado del conflicto bélico de 1948, en la arena política costarricense se lograron imponer los sectores de línea dura; aquellos que venían propugnando la lucha armada como el único medio para resolver las diferencias políticas. Sin embargo, la historia oficial ha disimulado la violencia que se produjo durante y después de la guerra civil. Esta versión ha enfatizado la figura de Figueres como un caudillo que construyó una institucionalidad para la cual la guerra fue un proceso indispensable. Más aún, la represión que vivieron los sectores perdedores ha sido invisibilizada, ya sea de manera directa o involuntaria. Las circunstancias en las cuales se produjo y concluyó el enfrentamiento han favorecido los silencios en torno a la represión y la violencia.

Sin embargo, investigadores como Díaz $(2015)$ y Solís $(2008,2013)$ han explorado problemáticas relacionadas con la memoria y la violencia vinculadas al conflicto bélico y a sus consecuencias. Han mostrado que las medidas de la Junta de Gobierno, encabezada por Figueres Ferrer, permitieron la persecución de los perdedores de la guerra, y que la forma de abordar estas secuelas, en los ámbitos social e intelectual, conllevó el silenciamiento de la represión vivida.

Esta violencia ha sido definida por Solís (2007-2008, p. 269) en términos de venganza y tragedia, como un contagio o un "mecanismo reactivo" que se expandió por la sociedad costarricense, sin posibilidad de ponérsele freno por vías institucionales. Situando este conflicto en perspectiva histórica, cabe señalar que el quiebre en la estabilidad política suscitado entre marzo y abril de 1948 no fue un elemento totalmente ajeno a la cultura política del país. La violencia política se había experimentado en Costa Rica en periodos precedentes: en la competencia electoral y en la disputa por el poder. Así ocurrió en 1917 cuando fue derrocado el gobierno de Alfredo González Flores, en 1932 con el "Bellavistazo", en 1944 con las protestas por el resultado de las elecciones y las acusaciones de fraude, y en 1947 con la huelga de brazos caídos asociada al reclamo por mayores garantías electorales. Todos ellos, casos que compartieron la salida violenta ante un conflicto político, en el cual los responsables fueron cobijados por la amnistía.

En la historia oficial estos sucesos han sido considerados como episodios infrecuentes dentro la dinámica del poder. Un disimulo acorde con el discurso de la excepcionalidad costarricense, que presenta al país como civilista y apegado al derecho, garante de una democracia electoral, donde se confía en los pactos políticos. Como resultado, cuando finalizó la guerra civil, los comunistas esperaban el cumplimiento de los acuerdos que aseguraban la amnistía, y no estaban preparados para enfrentar la violencia que recibieron (Díaz, 2015, p. 299). 
En este sentido, el abordaje de la represión experimentada por los comunistas durante los 18 meses del gobierno de la Junta, permite probar que los vanguardistas fueron objeto de una enérgica persecución por parte de las autoridades, pero la intensidad de estas acciones varió dependiendo de las condiciones inmediatas en las que se desenvolvían los diferentes actores sociales; existieron momentos álgidos de represión, encarcelamientos e incluso asesinatos, dinámica que se relacionó con los intentos de ataques externos o con los procesos electorales.

El lapso comprendido entre abril y junio de 1948, así como el mes de diciembre de ese año, fueron los instantes de mayor represión contra los comunistas. El primero al calor de la concluida confrontación bélica, y el segundo producto de la intentona de invasión calderonista desde Nicaragua. En abril de 1949 se vivieron otros momentos de violencia contra este grupo, a causa de la tentativa de golpe de Estado que Cardona articuló contra Figueres, y porque a nivel internacional también se recrudecieron las condiciones contra los comunistas, las cuales se expresaron de forma concreta en una oleada de ilegalización de estas agrupaciones en América Latina.

Los comunistas reaccionaron ante la represión tratando de valerse de los mecanismos que tuvieron a su alcance: dieron apoyo a sus familiares y amigos violentados, utilizaron los espacios legales que el sistema de justicia vigente en Costa Rica les permitía, como lo era el interponer una serie de recursos ante los tribunales con el fin de denunciar los encarcelamientos y la violencia que experimentaban. Además, los comunistas buscaron reorganizarse a nivel sindical y político mediante reuniones, al tiempo que recurrieron a la prensa nacional para denunciar los abusos que se cometían contra ellos, y circularon de manera clandestina ejemplares mimeografiados de Trabajo.

Por su parte, las autoridades justificaron su proceder perfilando a este grupo de personas como peligrosas, pues su comportamiento atentaba contra el orden nacional, ya que ponían en riesgo la lógica democrática y constitucional. Además, se trataba de aquellos individuos a quienes se acusaba de ser violentos durante el gobierno de Teodoro Picado (1944-1948). De este modo, la Junta de Gobierno encabezada por Figueres Ferrer respondía a los constantes llamamientos internos y externos que fomentaban el anticomunismo, así como a las demandas de sus seguidores.

Sin embargo, es importante mencionar que este contexto también se tornó complejo para Figueres, pues ciertos sectores que lo habían apoyado durante el conflicto bélico de 1948, con el transcurrir de los meses adversaron los proyectos de la Junta. Por esta razón, los nuevos opositores a Figueres habilitaron páginas en la prensa escrita para que los comunistas se manifestaran. Espacios que este sector aprovechó para exteriorizar su apoyo a las medidas económicas de la Junta, pero también para dejar 
constancia de la violencia política que como grupo estaban viviendo durante aquella coyuntura.

En términos generales, se favoreció el desarrollo de una fuerte campaña anticomunista dirigida desde los medios escritos, los cuales se encargaron de definir el comunismo como la amenaza más notoria y visible contra la paz de Costa Rica. En la creación de este sentimiento anticomunista coadyuvó la situación internacional en el inicio de la Guerra Fría, durante la cual, la persecución contra la izquierda en América Latina se manifestó en varios países mediante la intimidación, el encarcelamiento de los militantes y la prohibición de los partidos políticos.

La situación experimentada por los vanguardistas durante el gobierno de la Junta en Costa Rica, muestra una faceta de la historia contemporánea que no ha querido ser narrada, por resultar incómoda, al desmitificar la imagen heroica de los caudillos de la década de 1940, en particular de Figueres Ferrer; aunado a ello, por incluir en el debate social e historiográfico, la problemática de la persecución y el asesinato político, en un país que se ha imaginado históricamente como pacífico y conciliador, en contraste con otros contextos centroamericanos representados como impulsivos y crueles. La represión contra los comunistas tras la guerra civil, devela una parte de la violencia desatada en la arcadia.

\section{Referencias}

\section{Fuentes primarias}

Aguilar Hernández, Marielos. (2013). Álvaro Montero Vega: memorias de una vida y un tiempo de luchas y esperanzas. San José: Editorial de la Universidad de Costa Rica.

Archivo Judicial, Expediente No. 379 (1948).

Archivo Judicial, Expediente No. 380 (1948).

Archivo Judicial, Expediente No. 417 (1948).

Archivo Judicial, Expediente No. 424 (1948).

Archivo Judicial, Expediente No. 518 (1948).

Archivo Judicial, Expediente No. 656 (1948).

Archivo Judicial, Expediente No. 1 (1949).

Archivo Judicial, Expediente No. 5 (1949).

Archivo Nacional de Costa Rica. Judicial Remesa 1660 No. 39. Expediente No. 388 (1948). 
Archivo Nacional de Costa Rica. Gobernación. No. 41745 (1949).

Argüello, Rosendo. (1954). Quiénes y cómo nos traicionaron. México: Sin Editorial.

Asesinato de Eduardo Fernández Castro a manos del comunista Montiel. (29 de mayo de 1948). Diario de Costa Rica, p. 7.

Bajo interrogatorio del servicio de inteligencia el líder comunista Luis Carballo. (3 de junio de 1948). Diario de Costa Rica, p. 8.

Cabe otorgar la excarcelación en el caso de los detenidos por supuesta tenencia de propaganda subversiva. (12 de mayo de 1949). La Prensa Libre, p. 11.

Cerdas Cruz, Rodolfo. (2001). Entre el temor y la esperanza. En Mercedes Muñoz Guillén (Ed.). Niñas y niños del 48 escriben (Tomo I). San José: Editorial de la Universidad de Costa Rica.

Cerdas Mora, Jaime. (1993). La Otra Vanguardia: memorias. San José: Editorial de la Universidad Estatal a Distancia.

Chaves Molina, Fernando. (2002). Todos contra los comunistas. En Guillermo Villegas Hoffmeister (Comp.). El gobierno sobre las armas. San José: Editorial de la Universidad de Costa Rica.

Contesta Arnoldo Ferreto a Manuel Zúñiga Girón. (27 de febrero de 1949). Diario de Costa Rica, pp. 1 y 6.

Del malogrado complot, solo queda un saldo en poder del gobierno: mapas y armas. (6 de octubre de 1948). Diario de Costa Rica, pp. 1 y 3.

Denuncia violentos procedimientos de la policía el exdirigente comunista Carlos Luis Fallas. (6 de octubre de 1948). Diario de Costa Rica, p. 5.

Desde anoche se ordenó una "redada" de elementos Caldero-comunistas. (2 de octubre de 1948). La Prensa Libre, pp. 1 y 3.

Detenidos anoche y hoy los principales dirigentes del comunismo y el calderonismo. (19 de junio de 1948). La Prensa Libre, pp. 1 y 8.

Detenidos en la Penitenciaría que serán juzgados oportunamente para establecer sus actividades contra la libertad. (4 de mayo de 1948). La Prensa Libre, p. 1.

Disuelto el Partido Comunista Obrero de Colombia. (24 de junio de 1949). Diario de Costa Rica, p. 2.

El comunismo en abierta campaña de subversión. (1 de junio de 1948). Diario de Costa Rica, p. 8.

El Gobierno actual desaprueba absolutamente el atentado contra el señor Mora Valverde. (30 de abril de 1949). La Prensa Libre, pp. 1 y 8. 
El Presidente de Chile declara que acabará con el comunismo. (25 de junio de 1949). Diario de Costa Rica, p. 6.

El señor Presidente de la Junta de Gobierno visitó ayer los heridos recluidos en el Hospital San Juan de Dios. (9 de abril de 1949). La Nación, p. 5.

Emplazo al comunista Fallas para que pruebe debidamente sus cargos temerarios. (26 de mayo de 1948). Diario de Costa Rica, pp. 1 y 5.

Entrega del poder a Otilio Ulate. (21 de abril de 1949). Diario de Costa Rica, pp. 1 y 6.

Excluido el comunismo como partido político en México. (25 de mayo de 1949). Diario de Costa Rica, pp. 1 y 2.

Expulsión de líderes comunistas en El Salvador por estar alentando una huelga ilegal de los trabajadores ferroviarios la cual se mantiene todavía. (14 de mayo de 1949). La Nación, p. 4.

Fallas Sibaja, Carlos Luis. (1952). Carta enviada a la Asamblea Legislativa. Documento facilitado por Gerardo Contreras.

Fallas, Carlos Luis, Mora Enrique y Ferreto, Arnoldo. (s. f.). Calderón Guardia, José Figueres Ferrer y Otilio Ulate a la luz de los últimos acontecimientos políticos. San José: A. C.

Ferreto Segura, Arnoldo. (1984). Vida militante. San José: Editorial Presbere.

Ferreto Segura, Arnoldo. (1987). Gestación, consecuencias y desarrollo de los sucesos de 1948. San José: Ediciones Zúñiga y Cabal.

Figueres Ferrer, José. (1 de julio de 1948). Discurso pronunciado por Radio el martes 29 por el Presidente de la Junta de Gobierno don José Figueres. La Nación. pp. 12 y 13.

Fueron capturados ayer e internados en la Penitenciaría varios ciudadanos. (20 de junio de 1948). La Nación, p. 6.

Gran victoria del Partido Unión Nacional. Detenido en Heredia el líder comunista Fallas. (9 de diciembre de 1948). Diario de Costa Rica, pp. 1 y 4.

Herrera García, Adolfo, Mora Valverde, Enrique y Gamboa Guzmán, Francisco. (1971). Partido Vanguardia Popular, Breve esbozo de su historia. San José: Ediciones Revolución.

La propaganda clandestina del comunismo se intensifica en todo el país. (11 de agosto de 1948). Diario de Costa Rica, pp. 1 y 6.

Las autoridades sobre pista segura para dar con el centro distribuidor de propaganda subversiva. (25 de enero de 1949). La Prensa Libre, pp. 1 y 3. 
Llegaron ayer dos representantes de "Tiempo" y "Vida” de México. (1 de junio de 1948). Diario de Costa Rica, p. 1.

Los actos que ayer fueron criminales, ¿cometidos hoy no son execrables? (mayo de 1948). Trabajo No. 1, p. 1.

Los dirigentes de Vanguardia Popular nuevamente encarcelados. (junio de 1948). Trabajo No. 3, p. 3.

Manuel Mora afirmó ayer en Cuba que se le había hecho saber que sería más sano y estaría seguro si salía del país. (1 de mayo de 1948). Diario de Costa Rica, pp. 1 y 2.

Manuel Mora hecho preso en Panamá. (30 de abril de 1948). Diario de Costa Rica, pp. 1 y 6.

Mi hogar fue asaltado por las hordas gobiernistas que comandaba el célebre Horacio Montiel. (27 de mayo de 1948). Diario de Costa Rica, p. 4.

Mora Valverde, Eduardo. (s. f.). ¿100 años de democracia? De la clandestinidad a la libertad: 27 años de ilegalidad de los comunistas. San José: Litografía Cosmos S.A.

Mora Valverde, Eduardo. (2000). 70 años de militancia comunista. Recuerdos de Eduardo Mora Valverde. San José: Juricentro.

Ningún elemento responsable de Vanguardia Popular está comprometido ni en ese ni en ningún movimiento subversivo. (7 de octubre de 1948). Diario de Costa Rica, p. 5.

No fueron presos por razón del incendio. (19 de mayo de 1948), La Prensa Libre, p. 4.

No hubo violencia de la autoridad, ni siquiera restricción de actividades (26 de mayo de 1949). Diario de Costa Rica, p. 5.

No responder a la provocación con la locura. (mayo de 1948). Trabajo No. 1, p. 1.

Ortuño Sobrado, Fernando. (s. f.) ¿Por qué estuve en la guerra del 48? Recuperado de http://www.elespiritudel48.org/docu/h048.htm

Protestó la Corte contra escrito irrespetuoso del líder comunista Fallas para el presidente, Licenciado Guzmán Quirós. (25 de mayo de 1948). Diario de Costa Rica, pp. 1 y 8.

¿Qué hubo en el asesinato del diputado Filiberto Chavarría? (julio de 1948). Trabajo No. 6, p. 3.

Quiero hacer pública protesta por medio de su periódico. (5 de octubre de 1948). Diario de Costa Rica, p. 3. 
Reconoce la Asamblea Nacional Constituyente que las medidas de seguridad pública se cumplen sin violencia. (26 de mayo de 1949). Diario de Costa Rica, pp. 1 y 8.

Sáenz Ferreto, Elsa y Sáenz Ruiz, Nidia. (1998). Mis recuerdos del 48. Una toma de conciencia. En Elsa Sáenz Ferreto et al. Otras voces del 48. Heredia: Editorial de la Universidad Nacional.

Salas, Addy. (1998). Con Manuel: devolver al pueblo su fuerza. San José: Editorial de la Universidad de Costa Rica.

¡Salud, resistentes! (julio de 1948). Trabajo No. 6, p. 3.

Siguen las detenciones de elementos comunistas. (8 de agosto de 1948). La Prensa Libre, pp. 1 y 10.

Somoza vino a Costa Rica, un arsenal en la casa del comunista Valerín. (25 de abril de 1948). Diario de Costa Rica, p. 4.

Sorprendidos 15 comunistas con propaganda subversiva. (25 de marzo de 1949). Diario de Costa Rica, pp. 1 y 2.

Valverde Monge, José Eliseo. (2001). Un niño policía. En Mercedes Muñoz Guillén. (Ed.), Niñas y niños del 48 escriben. (Tomo I). San José: Editorial de la Universidad de Costa Rica.

Vargas, Óscar. (s. f.). Informe sobre la situación política nacional; antecedentes y perspectivas. S.p.i. Documento facilitado por Gerardo Contreras.

Venegas Campos, R. (1º de mayo de 1949). Al violar mi casa en busca de Villalobos amenazaron con matarme y formulo Hábeas Corpus en su favor. La Nación, p. 9.

\section{Fuentes secundarias}

Acuña Valerio, Miguel. (1990). El 48. San José: Litografía e imprenta Lil.

Acuña Valerio, Miguel. (1997). La Junta y los mitos del 48. San José: Ediciones Sanabria.

Benavides Chaverri, Enrique. (1968). Casos célebres: casuística criminal. San José: Fotorama.

Contreras, Gerardo y Cerdas, José Manuel. (1988). Los años 40's: historia de una política de alianzas. San José: Editorial Porvenir.

Contreras Álvarez, Gerardo. (2010). Semblanzas de luchadores sociales del Partido Vanguardia Popular. San José: Editorial Estudios Contemporáneos. 
Díaz Arias, David. (2015). Crisis social y memorias en lucha: guerra civil en Costa Rica, 1940-1948. San José: Editorial de la Universidad de Costa Rica.

Fallas Sibaja, Carlos Luis. (2013). De mi vida. (Tomo II). Introducción Iván Molina. Heredia: Editorial de la Universidad Nacional.

González Ortega, Alfonso. (2005). Mujeres y hombres de la posguerra costarricense (1950-1960). San José: Editorial de la Universidad de Costa Rica.

Meyer, Lorenzo. (abril-junio, 2010). "Relaciones México-Estados Unidos. Arquitectura y montaje de las pautas de la Guerra Fría, 1945-1964". Foro Internacional, 50(2). Recuperado de http://www.redalyc.org/ pdf/599/59921039002.pdf

Molina Jiménez, Iván. (2000). ¿De vuelta a los 8 años? A propósito de La guerra de Figueres de Guillermo Villegas Hoffmeister. Revista de Historia, (41), pp. 191-198.

Molina Jiménez, Iván. (2005). Prensa, propaganda electoral y comunismo en Costa Rica durante las décadas de 1930 y 1940. Estudios sobre el Mensaje Periodístico, (11), pp. 407-423.

Molina Jiménez, Iván. (2011). La producción impresa del Partido Comunista de Costa Rica (1931-1948). Iberoamericana, XI(41), pp. 43-56.

Molina Jiménez, Iván. (2016). Príncipes de las remotidades: Carlos Luis Fallas y los escritores proletarios costarricenses del siglo XX. San José: Editorial de la Universidad Estatal a Distancia.

Molina Vargas, Silvia Elena. (2017). Los asesinatos del Codo del Diablo (19491951). En Iván Molina y David Díaz (Eds.), El verdadero anticomunismo, política, género y guerra fría en Costa Rica (1948-1973). San José: Editorial de la Universidad Estatal a Distancia.

Pérez Delgado, Nicolás. (1998). Volando bala 1948. San José: Composiciones Culturales Macondo S.A.

Quirós Vargas, Claudia. (1989). Los Tribunales de Probidad y de Sanciones Inmediatas (de junio 1948 a noviembre de 1949). San José: Editorial Costa Rica.

Rodríguez Vega, Eugenio. (2003). Biografía de Costa Rica. San José: Editorial Costa Rica.

Salazar Mora, Jorge Mario. (1981). Política y reforma en Costa Rica. San José: Editorial Porvenir.

Schifter Sikora, Jacobo. (1985). La fase oculta de la Guerra Civil en Costa Rica. San José: Editorial Universitaria Centroamericana. 
Servín, Elisa. (enero-junio, 2004). Propaganda y Guerra Fría: la campaña anticomunista en la prensa mexicana del medio siglo. Signos Históricos, 11(21). Recuperado de http://www.redalyc.org/pdf/344/34401101.pdf

Solís Avendaño, Manuel. (2007-2008). El 48 como desborde trágico. Anuario de Estudios Centroamericanos, (33-34), 261-295.

Solís Avendaño, Manuel. (2008). La institucionalidad ajena: los años 40 y el fin de siglo. San José: Editorial de la Universidad de Costa Rica.

Solís Avendaño, Manuel. (2013). Memoria descartada y sufrimiento invisibilizado: la violencia política de los años 40 vista desde el Hospital Psiquiátrico. San José: Editorial de la Universidad de Costa Rica.

Tovar, Enrique. (2008). Antes, durante y después de la guerra civil del 48. Heredia: Litografía Morales.

Villegas Hoffmeister, Guillermo. (1998). La guerra de Figueres: crónica de ocho años. San José: Editorial de la Universidad Estatal a Distancia.

Zúñiga Díaz, Francisco. (1991). Carlos Luis Sáenz, el escritor, el educador y el revolucionario. San José: Litografía Ipeca. 